\title{
Un trastorno poco frecuente del ciclo de la urea en un recién nacido: deficiencia de $\mathbf{N}$-acetilglutamato sintasa
} A rare urea cycle disorder in a neonate: $N$-acetylglutamate synthetase deficiency

\author{
Dra. Asburce Olgac ${ }^{a}$, Dra. Çiğdem S. Kasapkara ${ }^{a}$, Dr. Mustafa Kilic ${ }^{a}$, Dra. Betul E. Derinkuyu \\ Dra. Ebru Azapagasic, Dr. Selman Kesicic, Dra. Gürsel Biberoğlu ${ }^{d}$ Dr. Ahmet Ozyazicie, Dra. Meryem Karaca \\ y Dr. Johannes Haberles
}

\section{RESUMEN}

Los trastornos del ciclo de la urea (TCU) son enfermedades hereditarias con un posible desenlace desfavorable por hiperamoniemia grave. Se informa de una bebé con deficiencia deN-acetilglutamato sintasa (NAGS), quien tenía succión débil e hipotonicidad. Al examinarla, se observó hepatomegalia. El hemograma, los análisis y la gasometría eran normales, y las proteínas de la fase aguda, negativas. En los análisis, no se observaron cetonas en sangre, pero sí concentraciones elevadas de amoníaco. Las pruebas metabólicas no fueron concluyentes. Seinició el tratamiento de emergencia inmediatamente y recibió el alta el día 15 después del ingreso. Se confirmó deficiencia de NAGS mediante análisis de ADN. La paciente no tiene restricciones alimentarias ni toma medicamentos, excepto $\mathrm{N}$-carbamil glutamato (NCG). La deficiencia de NAGS es el único TCU que puede tratarse específica y eficazmente con NCG. La detección temprana permiteiniciar un tratamiento temprano y evitar los efectos devastadores de la hiperamoniemia. Palabras clave: trastornos del ciclo de la urea, congénito, deficiencia de $N$-acetilglutamato sintasa, hiperamoniemia.

a. División de Metabolismo Pediátrico, Hospital de Formación e Investigación en Salud y Enfermedades Materno Infantiles Dr. Sami Ulus, Ankara, Turquía.

b. División de Radiología Pediátrica, Hospital de Formación e Investigación en Salud y Enfermedades Materno Infantiles Dr. Sami Ulus, Ankara, Turquía.

c. Unidad de cuidados intensivos pediátricos, Hospital de Formación e Investigación en Salud y Enfermedades Materno Infantiles Dr. Sami Ulus, Ankara, Turquía.

d. División de Metabolismo y Nutrición en Pediatría, Hospital de Gazi Üniversitesi, Ankara, Turquía.

e. División de Neonatología, Hospital de Formación e Investigación en Salud y Enfermedades Materno Infantiles Dr. Sami Ulus, Ankara, Turquía.

f. División de Metabolismo Pediátrico, Hospital de Harran Üniversitesi, Sanliurfa, Turquía.

g. División de Metabolismo, Hospital Pediátrico Universitario, Zúrich, Suiza.

Correspondencia:

Dra. Asburce Olgac: mabolgac@yahoo.com

Financiamiento: Ninguno.

Conflicto de intereses: Ninguno que declarar.

Recibido: 17-6-2020

Aceptado: 13-7-2020 http:/ / dx.doi.org/10.5546/ aap.2020.e545

Texto completo en inglés:

http:/ / dx.doi.org/10.5546/ aap.2020.eng.e545

Cómo citar: Olgac A, Kasapkara CS, Kilic M, Derinkuyu BE, et al. Un trastorno poco frecuente del ciclo de la urea en un recién nacido: deficiencia de $\mathrm{N}$-acetilglutamato sintasa. Arch Argent Pediatr 2020;118(6):e545-e548.

\section{INTRODUCCIÓN}

Los trastornos del ciclo de la urea (TCU), causados por la deficiencia de enzimas o transportadores involucrados en el ciclo de la urea, son enzimopatías congénitas hereditarias con presentaciones clínicas variables. La deficiencia grave de enzimas suele asociarse a hiperamoniemia grave, con alimentación deficiente, vómitos, letargo, taquipnea, convulsiones y coma, especialmente durante el período neonatal. En el caso de deficiencias más leves, situaciones catabólicas como enfermedades o estrés pueden desencadenar la hiperamoniemia, las cuales pueden presentarse a cualquier edad. La mayoría de los TCU en el período neonatal suelen diagnosticarse incorrectamente como sepsis neonatal. Los niños y los adultos con deficiencias parciales también pueden tener síntomas neurológicos o psiquiátricos, que incluyen cefalea, cambios de comportamiento, confusión y vómitos cíclicos. ${ }^{1}$

La N-acetilglutamato sintasa (NAGS) es una de las enzimas involucradas en el ciclo de la urea y cataliza la formación del $\mathrm{N}$-acetilglutamato (NAG) usando como sustratos glutamato y acetilCoA. La deficiencia de NAGS probablemente sea uno de los TCU menos frecuentes, con apenas más de 50 casos publicados en todo el mundo. ${ }^{2} \mathrm{El}$ tratamiento más eficaz es el $\mathrm{N}$-carbamil glutamato (NCG), que corrige la hiperamoniemia y posibilita la ureagénesis. ${ }^{3}$

En el presente artículo, se informa el caso de una recién nacida con diagnóstico de deficiencia de NAGS. 


\section{Descripción del caso}

En una clínica externa, a los 5 días de vida, se evaluó a una bebé nacida a término con un peso de 2500 g debido a succión débil e hipotonicidad. Se trataba de la primera hija viva de padres consanguíneos (primos hermanos) de origen turco. El primer hijo de la pareja había fallecido repentinamente a los 2 días de vida por una etiología desconocida. En el caso descrito en el presente artículo, primero se sospechó sepsis neonatal, y se ingresó a la recién nacida en la unidad de cuidados intensivos neonatales. Los valores del hemograma completo, los análisis bioquímicos de rutina y la gasometría eran normales, y las proteínas de la fase aguda, negativas. Se la hidrató por vía intravenosa y, para descartar meningitis, se le realizó una punción lumbar, con la cual se observaron valores microscópicos y bioquímicos normales en el líquido cefalorraquídeo (LCR). Se inició la administración de antibióticos parenterales. Dado que el estado general de la paciente no mejoró tras la rehidratación, se realizaron análisis de laboratorio adicionales, en los que no se observaron cetonas en la sangre, pero sí concentraciones elevadas de amoníaco (937 $\mu \mathrm{mol} / 1$; valor normal: $<150 \mu \mathrm{mol} / 1)$. Ante la sospecha de una enzimopatía congénita, se la derivó a nuestro centro a los 10 días de vida.

Cuando ingresó, su estado general era malo y estaba siendo ventilada. El peso y la talla se encontraban dentro de los percentiles bajos/ normales. En el examen físico, se observó hepatomegalia (hígado palpable a $4 \mathrm{~cm}$ por debajo del margen costal inferior). En los análisis de laboratorio iniciales, se observó hiperamoniemia $(2404 \mu \mathrm{mol} / \mathrm{l})$ y parámetros de coagulación anormales.

Se inició la administración de fármacos destinados a disminuir la concentración de amoníaco, entre otros, benzoato de sodio $(250 \mathrm{mg} / \mathrm{kg})$ mediante inyección intravenosa rápida y NCG por sonda nasogástrica. Dado que la paciente no contaba con un diagnóstico específico, se le administraron L-carnitina y biotina por vía oral e hidroxocobalamina por vía intramuscular, de conformidad con las pautas más recientes para el tratamiento de la hiperamoniemia. ${ }^{3}$

FIGURA 1. RM de cerebro: en la secuencia FLAIR en plano axial (a), se observa un aumento de la intensidad de señal en el núcleo caudado y el putamen (flechas blancas) y la corteza insular (flechas negras) en ambos hemisferios. Cabe señalar que la alteración de la señal se extiende hacia las regiones perirrolándicas (flechas blancas) y la corteza prefrontal en ambos hemisferios (b). En la RM ponderada en T2, en plano axial (c), se observa un acortamiento de la señal en T2 en el putamen, el globo pálido y el núcleo ventral lateral del tálamo (flechas blancas) con un tamaño reducido. En la resonancia magnética con coeficiente de difusión aparente, en plano axial (d), se observa una difusión restringida en el putamen y el tálamo (flechas blancas), la cual se observa como una señal oscura.

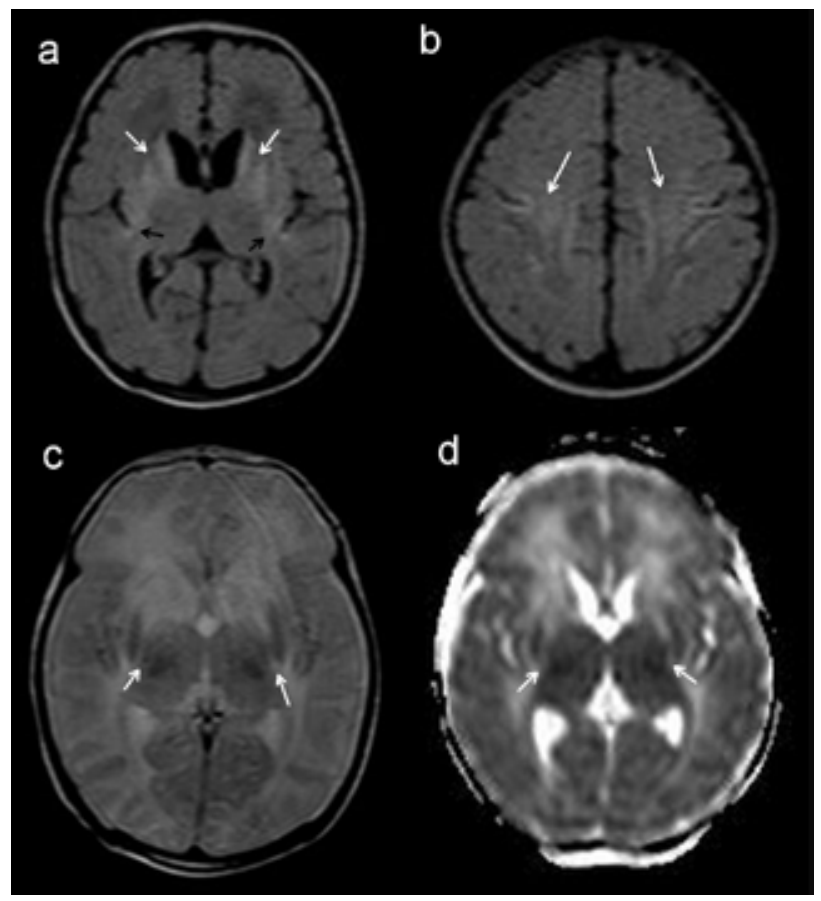


Se realizó una RM de cerebro, donde se observó un aumento de la intensidad de señal en el núcleo caudado, el putamen y la corteza insular en ambos hemisferios (Figura 1).

En las pruebas metabólicas, se observó un perfil de acilcarnitinas normal en el análisis de la muestra de sangre seca. En cuanto a la concentración plasmática de aminoácidos, se observó un leve aumento de la alanina (496 $\mu \mathrm{mol} / \mathrm{l}$; intervalo normal: 143-439), valores normales de glutamina $(363 \mu \mathrm{mol} / 1$; intervalo normal: $246-1182)$ y arginina ( $54 \mu \mathrm{mol} /$; intervalo normal: 12-133) y una disminución de la citrulina ( $2 \mu \mathrm{mol} /$; intervalo normal: 3-35). Los resultados de los análisis de aminoácidos y ácidos orgánicos en orina eran normales. La actividad de la biotinidasa estaba dentro de los límites normales. Por lo tanto, se sospechó principalmente de un TCU proximal, ya sea por deficiencia de NAGS o de carbamil fosfato sintetasa I (CPSI), dado que los hallazgos de los análisis de acilcarnitinas y aminoácidos no eran concluyentes. Se le dio el alta el día 15 desde la fecha de ingreso y se indicó una dieta limitada en proteínas, $250 \mathrm{mg} / \mathrm{kg} /$ día de benzoato de sodio y $50 \mathrm{mg} / \mathrm{kg} /$ día de NCG.

La deficiencia de NAGS se confirmó mediante un análisis de $\mathrm{ADN}$, donde se identificó una mutación homocigota de aminoácido conocida: c.1450T>C (p.Trp484arg) en el exón 6 del gen NAGS. Se determinó que el padre y la madre eran portadores heterocigotos de la mutación.

Luego de reducir gradualmente el tratamiento farmacológico, a excepción del NCG (30 mg/ $\mathrm{kg}$ / día), la paciente no tiene ninguna restricción alimentaria ni toma otros medicamentos. Ahora tiene un año y medio y tiene cierto grado de retraso global, pero ha logrado avances importantes y no ha tenido más episodios de hiperamoniemia desde que se inició la administración de NCG.

\section{DISCUSIÓN}

La deficiencia de NAGS es el TCU menos frecuente (representa entre el $0,5 \%$ y el $1 \%$ de todos los TCU) y puede causar efectos graves en el sistema neurológico del recién nacido por hiperamoniemia grave, según su duración e intensidad..$^{1-3}$ Se sabe que el pronóstico es malo si las concentraciones de amoníaco superan los $1000 \mu \mathrm{mol} / 1 .^{3} \mathrm{El}$ diagnóstico diferencial incluye otras enzimopatías congénitas (p. ej., aciduria orgánica) y otras afecciones que provocan hiperamoniemia (p. ej., sepsis, insuficiencia hepática, infecciones congénitas, intoxicaciones exógenas, determinados fármacos, shunt portocava, síndrome de Reye, afecciones con catabolismo de proteínas y suministro excesivo de nitrógeno debido a la nutrición parenteral). Los recién nacidos prematuros pueden tener hiperamoniemia transitoria por shunt venoso de la sangre portal. ${ }^{3}$

Como los efectos de la hiperamoniemia pueden ser devastadores, se debe iniciar de inmediato el tratamiento, que incluye el cese de la ingesta de proteínas, la infusión continua de altas dosis de glucosa por vía parenteral y la administración de fármacos depuradores de nitrógeno. En función de la etiología preexistente, los fármacos que pueden usarse para tratar la hiperamoniemia son los depuradores de nitrógeno (benzoato de sodio, fenilbutirato de sodio, fenilacetato de sodio), la L-arginina y el NCG. En determinados pacientes, otra opción de tratamiento a largo plazo para los TCU es el trasplante hepático. El NCG es un fármaco sintético y un análogo del NAG humano. ${ }^{3} \mathrm{La}$ hiperamoniemia por deficiencia de NAGS puede tratarse con eficacia con NCG, y es posible que no se requiera ninguna restricción alimentaria, al menos cuando no se está frente a una situación catabólica. ${ }^{4,5}$ Se sugirió agregar NCG al protocolo de tratamiento estándar de la hiperamoniemia junto con benzoato de sodio, fenilbutirato de sodio y L-arginina. ${ }^{3}$

El análisis genético es la técnica diagnóstica de referencia para la deficiencia de NAGS, ${ }^{3}$ ya que las pruebas habituales de detección de trastornos metabólicos pueden no ser concluyentes. El gen NAGS se encuentra en el cromosoma 17, en la banda 17q21.31. Hasta ahora se han descrito al menos 45 mutaciones diferentes del gen NAGS.2,6 Al Kaabi y cols., revisaron el espectro clínico y molecular de 41 mutaciones diferentes en el gen NAGS y observaron que, en el $60 \%$ de los casos, se trataba de mutaciones de aminoácidos; en el $10 \%$, de mutaciones terminadoras; en el $20 \%$, de mutaciones del marco de lectura y, en el $10 \%$, de mutaciones del sitio de empalme. ${ }^{6}$ En el caso de nuestra paciente, se trata de una mutación de aminoácido ya conocida, que causa crisis de hiperamoniemia en el período neonatal. $2,5,7$ Se debe realizar el diagnóstico genético para confirmar la enfermedad y para ofrecer pruebas prenatales y diagnóstico genético preimplantatorio para futuros hijos de los padres.

La paciente ahora tiene un año y medio y presenta un retraso en el desarrollo motriz y mental. El tratamiento para la hiperamoniemia 
se inició de forma relativamente tardía (el día 10 de vida), cuando probablemente ya habían comenzado los efectos catastróficos de la hiperamoniemia. Reigstad y cols. ${ }^{8}$ informaron el caso de una bebé con hiperamoniemia grave (2235 $\mu \mathrm{mol} / 1)$, cuya causa resultó ser deficiencia de NAGS. En ese caso, se inició la administración de NCG el día 4 de vida y los resultados posteriores de desarrollo neurológico fueron normales. En el caso de nuestra paciente, una vez iniciada la administración de NCG, no se observaron más episodios de hiperamoniemia y no hay ninguna restricción alimentaria. Si bien el NCG evitó un mayor deterioro mental, nuestro caso es un ejemplo de los efectos indeseados de la hiperamoniemia cuando se retrasan el diagnóstico y el tratamiento. Además, quisiéramos destacar la necesidad de evaluar la hiperamoniemia de forma inmediata e iniciar el tratamiento de emergencia con fármacos depuradores de nitrógeno y NCG.

Quisiéramos recalcar la importancia de las pruebas de detección de trastornos metabólicos (incluida la concentración de amoníaco) en los recién nacidos con hallazgos de sepsis. Los pediatras deben estar al tanto de los signos de intoxicación de las enzimopatías congénitas, ya que este tipo de trastornos metabólicos puede tratarse eficazmente tomando ciertas medidas si el diagnóstico es oportuno. Se debe realizar una anamnesis detallada de los padres, específicamente con preguntas sobre los antecedentes de endogamia y fallecimiento de hermanos, ya que estos puntos pueden ser indicativos de enzimopatías congénitas. Se debe garantizar un asesoramiento familiar para padres con antecedentes de fallecimiento de hijos sin explicación, ya que es probable que requieran un diagnóstico genético preimplantatorio.

En conclusión, la deficiencia de NAGS es el único trastorno del ciclo de la urea que puede tratarse de forma específica y eficaz con NCG, sin restricciones alimentarias. La detección precoz de la enfermedad permite iniciar un tratamiento temprano que puede evitar los efectos devastadores de la hiperamoniemia e influir de forma positiva en la evolución.

\section{REFERENCIAS}

1. Wijburg FA, Nassogne MC. Disorders of the urea cycle and related enzymes. En: Saudubray JM, van den Berghe G, Walter JH (Eds). Inborn Metabolic Diseases. Berlin Heidelberg: Springer; 2012.Págs.297-310.

2. Sancho-Vaello E, Marco-Marin C, Gougeard N, FernándezMurga L, et al Understanding $\mathrm{N}$-acetyl-L-glutamate synthase deficiency: mutational spectrum, impact of clinical mutations on enzyme functionality, and structural considerations. Hum Mutat. 2016; 37(7):679-94.

3. Häberle J, Boddaert N, Burlina A, Chakrapani A, et al. Suggested guidelines for the diagnosis and management of urea cycle disorders. Orphanet J Rare Dis. 2012; 7:32.

4. Gessler P, Buchal P, Schwenk HU, Wermuth B. Favourable long-term outcome after immediate treatment of neonatal hyperammonemia due to $\mathrm{N}$-acetylglutamate synthase deficiency. Eur J Pediatr. 2010; 169(2):197-9.

5. Van Leynseele A, Jansen A, Goyens P, Martens G, et al. Early treatment of a child with NAGS deficiency using $\mathrm{N}$-carbamyl glutamate results in a normal neurological outcome. Eur J Pediatr. 2014; 173(12):1635-8.

6. Al Kaabi EH, El-Hattab AW. N-acetylglutamate synthase deficiency: Novel mutation associated with neonatal presentation and literature review of molecular and phenotypic spectra. Mol Genet Metab Rep. 2016; 8:94-8.

7. Häberle J, Denecke J, Schmidt E, Koch HG. Diagnosis of $\mathrm{N}$-acetylglutamate synthase deficiency by use of cultured fibroblasts and avoidance of nonsense-mediated mRNA decay. J Inherit Metab Dis. 2003; 26(6):601-5.

8. Reigstad H, Woldseth B, Häberle J. Normal neurological development during infancy despite massive hyperammonemia in early treated NAGS deficiency. JIMD Rep. 2017; 37:45-7. 